\title{
- Como enfrentar a desinformação científica? Desafios sociais, políticos e jurídicos intensificados no contexto da pandemia
}

\author{
How to face scientific misinformation? Social, political and legal \\ challenges intensified in the context of the pandemic
}

\begin{abstract}
Thaiane Moreira de Oliveira ${ }^{a}$,
RESUMO: A desinformação relacionada à ciência tem sido uma das grandes preocupações atuais e os desafios para enfrentá-la tem se intensificado neste momento em que o mundo atravessa uma pandemia. A proposta deste artigo é problematizar e refletir sobre as formas como a agenda da desinformação tem sido construída, buscando discutir as ameaças ao sistema democrático. Através de revisão de literatura e análise da conjuntura política brasileira, este artigo se desdobra a partir dos seguintes eixos: 1) fatores culturais, políticos e ideológicos que tornam a desinformação um campo fértil para a dúvida e a descrença; 2) as medidas de enfrentamento à desinformação e suas limitações. 3) o processo de descrença institucional propiciada em um cenário político de contestação epistêmica e o papel da mídia nesta atuação; 4) uma agenda de guerra híbrida instaurada no campo político e jurídico, que ameaça o sistema democrático atual em nome de um inimigo indefinido: a desinformação; Por fim, este artigo busca oferecer um panorama amplo sobre os desafios e dificuldades para o campo da comunicação e informação no enfrentamento à desinformação relacionada à ciência em um contexto atual de disputas informacionais, políticas, jurídicas e tecnológicas.
\end{abstract}

Palavras-chave: Desinformação; Desinformação Científica; Conjuntura.

ABSTRACT: Disinformation related to science has been a major concern nowadays and the challenges to face it have intensified at a time when the world is going through a pandemic. The purpose of this article is to problematize and reflect on the ways in which the disinformation agenda has been constructed, seeking to discuss the threats to the democratic system. Through literature review and analysis of the Brazilian political situation, this article unfolds from the following axes: 1) cultural, political and ideological factors that make disinformation a fertile field for doubt and disbelief; 2) actions to deal with disinformation and its limitations. 3) the process of institutional disbelief brought about in a political scenario of epistemic contestation and the role of the media in this performance; 4) a hybrid war agenda established in the political and legal field, which threatens the current democratic system in the name of an undefined enemy: disinformation; Finally, this article seeks to offer a broad overview of the challenges and difficulties in the field of communication and information in addressing science-related disinformation in a current context of informational, political, legal and technological disputes.

Keywords: Disinformation; Scientific Misinformation; Conjuncture.

\footnotetext{
a Programa de Pós-graduação em Comunicação, Universidade Federal Fluminense, Niterói, RJ, Brasil.

*Correspondência para/Correspondence to: Thaiane Moreira de Oliveira. E-mail: thaianeoliveira@id.uff.br. Endereço institucional: R. Alexandre Moura, 8 - Bloco A, sala 403b - São Domingos, Niterói - RJ, 24210-200.

Recebido em/Received: 15/08/2020; Aprovado em/Approved: 16/12/2020.
}

Preprint do artigo autoarquivado em 25/11/2020, em SciELO Preprints: https://doi.org/10.1590/SciELOPreprints.1505

Artigo publicado em acesso aberto sob licença $\mathrm{CC}$ BY 4.0 Internacional $@()$ 


\section{INTRODUÇÃO}

Em 15 fevereiro de 2020, a Organização Mundial de Saúde (OMS) anunciou que estávamos atravessando não apenas uma pandemia, mas também uma infodemia, que representa um sério problema para a saúde pública, já que as pessoas precisam de orientação e informações para saber quais ações devem ser tomadas para proteger a si e aos outros e ajudar a mitigar o impacto de uma doença (OMS, 2020). Segundo a OMS, esta infodemia, que se caracteriza como uma superabundância informacional, muitas vezes precisas outras não, dificultam as pessoas a encontrar fontes e orientações confiáveis quando precisam delas, podendo colocar em risco a saúde da população. Nesta superabundância informacional, instituições científicas, cientistas e divulgadores de ciência, políticos, organizações governamentais e nãogovernamentais e uma sorte de atores que muitas vezes vão de encontro ao conhecimento científico, disputam o espaço digital na disseminação de narrativas sobre ciência.

Este tem sido um grande desafio, sobretudo porque não se trata de falta de informações, mas um conjunto de crenças consolidadas que vão de encontro com valores estabelecidos em torno das instituições científicas como espaço de produção de informações confiáveis e evidências para tomada de decisão. Este conjunto de crenças está atrelada a um processo político e ideológico voltado para a descrença sobre instituições epistêmicas, ou seja, instituições cuja função social originalmente estabelecida se consolidou em torno da produção ou disseminação de conhecimento e informações, como as escolas, universidades, instituições de pesquisa científica e o jornalismo. Autores como Seumas Miller (2020) defendem que instituições epistêmicas são aquelas que têm um papel fundamental não apenas em garantir que os cidadãos sejam reflexivos e bem informados, mas também em ajudar a garantir que o discurso público seja conduzido de acordo com as normas epistêmicas constitutivas da investigação racional livre e aberta, e consistente com o exercício adequado do direito de buscar livremente a verdade. Neste cenário, campanhas são desenvolvidas como estratégias para restaurar confiança já abalada junto à sociedade, num movimento de defesa pela credibilidade dessas instituições epistêmicas. Jornalistas e cientistas, de maneira romântica e apaixonada, se unem em campanhas e editoriais para reforçar o seu papel de produtores da "verdade" como única fonte de confiança possível. Porém, tangenciam do debate as disputas que se travam sobre a informação produzidas pelas mesmas no campo político e suas relações exógenas ao campo, tirando do centro de discussão a responsabilidade dessas próprias instituições no processo de descredibilização de sua própria autoridade. Essa desconfiança sobre as instituições epistêmicas, carregada de um discurso moral sobre a corrupção (Mede, Schäfer, 2020), deriva, sobretudo, de uma percepção pública sobre dimensões éticas de seus membros, sobre interesses particulares e na relação com atores exógenos ao campo. $\mathrm{Na}$ ciência, os principais argumentos desta descrença generalizada se inserem na desconfiança sobre as relações entre cientistas e instituições científicas com o setor industrial, como a indústria farmacêutica, por exemplo, além de estreitamento com lobbies políticos (Oliveira et al, 2020). Mais do que apelo à confiança e credibilidade, torna-se necessário, portanto entender como essa profusão de informações circulam, as motivações para

Ainda de acordo com o relatório da OMS publicado em abril deste ano, embora a infodemia seja um grande desafio para a resposta ao surto, ele apresenta uma oportunidade de identificar e adaptar novas ferramentas de preparação e resposta. No entanto, os desafios para produzir respostas efetivas frente a essa profusão informacional exigem um grande trabalho multidisciplinar e em conjunto a vários 
setores da sociedade, buscando uma compreensão ampla sobre o tópico para entender as disputas inerentes à circulação da informação relacionada à ciência e as implicações sociais, culturais, políticas e jurídicas no enfrentamento à desinformação.

Diante disso, a proposta deste artigo vai ao encontro desta urgência de apresentar um diagnóstico sobre a desinformação e as disputas epistêmicas no enfrentamento à desinformação relacionada à ciência no contexto de pandemia. Trazendo um debate sobre os desafios frente a um movimento de ceticismo e desconfiança sobre as instituições epistêmicas, além da politização da ciência e uma agenda de guerra híbrida que se desponta no debate público, este artigo lança um olhar sobre a conjuntura política brasileira.

Assim, este artigo se desdobra em quatro partes. Na primeira discutiremos os limites conceituais da desinformação, pautados na intencionalidade ou a partir de um reforço sobre a confiança em fontes institucionais epistêmicas legitimadas. Ao transpor a construção conceitual para o outro polo do processo comunicativo, a recepção, no segundo tópico traremos estudos multidisciplinares para entender as implicações a partir de ações em três tipos de abordagem para o enfrentamento à desinformação: as ferramentas de checagem de fatos e verificação de informações, uma segunda abordagem ancorada em teorias deliberativas e por fim, iniciativas de letramento midiático e informacional. Apresentaremos ainda algumas pistas multidisciplinares para enfrentar a desinformação a partir de estudos realizados por outros pesquisadores em outros contextos. Apesar de serem pistas importantes para este fenômeno complexo, torna-se necessário entender os contextos a partir do cenário brasileiro. Assim, na terceira parte desta discussão, apresentaremos o contexto da crise epistêmica, tendo como eixo central de discussão um processo de descrença sobre as instituições produtoras e disseminadoras de conhecimento e informação e o crescimento do conservadorismo no Brasil, que instaura uma agenda de guerra de combate à desinformação. Por fim, debateremos, a partir da conjuntura política brasileira, como esta agenda de guerra tem se instalado nos Três Poderes e as disputas que se desdobram no campo político, legislativo e judiciário para enfrentar a desinformação. Por fim, este artigo busca oferecer um panorama amplo sobre os desafios e dificuldades para o enfrentamento à desinformação relacionada à ciência e no desvelamento de agendas autoritárias em um contexto atual de disputas informacionais, políticas, jurídicas e tecnológicas.

\section{DESINFORMAÇÃO: EM BUSCA DE UM CONCEITO PARA ALÉM DA INTENCIONALIDADE}

A desinformação relacionada à ciência tem sido uma das grandes preocupações mundiais, sobretudo em tópicos controversos para a comunidade científica, como aquecimento global e mudanças climáticas (Lubchenco, 2017) e vacinação (Gostin, 2014). Como pôde ser acompanhado durante a pandemia de Covid-19, inúmeras informações falsas foram compartilhadas, inclusive em discursos de lideranças políticas, levando aos hospitais em vários países a atenderem centenas de casos de intoxicação de substâncias que surgiram a partir de promessas de curas milagrosas nos ambientes digitais (Catraca, 2020).

Temas como fake news e pós-verdade têm proliferado no debate público, na agenda midiática e na própria academia. Muito da literatura científica tende a associar a desinformação a um conjunto de elementos fixos para identificá-la a partir de tipologias. É o caso de Fallis (2015) que as define a partir de instâncias prototípicas elaboradas com a função de enganar. Wardle \& Derakshan (2017) propõem um 
conceito de desordem informacional a partir de um conjunto de três estruturas semânticas que no inglês permite a distinção entre misinformation, disinformation e mal-information, no qual a intencionalidade para o engano está presente nas três distinções. Partem do princípio de um ordenamento de circulação informacional, a partir de matrizes pautadas na produção, no tipo de mensagem e na recepção. A matriz de análise proposta pelos autores Wardle e Derakshan parte de uma ideia funcionalista no qual um produtor emite uma mensagem, a partir de uma estrutura textual própria, que vai ser decodificado pelos sujeitos, como uma ordem natural do processo comunicativo. Portanto, nesta visão, é necessário olhar para o polo da produção e deduzir sobre a intencionalidade de enganar os sujeitos e, b) no máximo, no conteúdo e no formato da mensagem, para identificar a desinformação'. Nesta perspectiva, derivada de um modelo linear do campo da comunicação, se identificada a forma, pode-se deduzir sobre a intenção dos sujeitos. Mas como provar a intencionalidade de enganar, sem ferir o regime democrático, em uma sociedade baseada em uma tra dição inquisitorial (Kant de Lima, 1995), que pode lançar mão de instrumentos coercitivos como "forma legítima de produzir uma verdade judiciária confiável, com a revelação do acusado não só dos atos cometidos, mas, principalmente, de suas intenções ao cometê-los" (Kant de Lima, Mousinho, 2018, p. 253)? Tal agenda de enquadramento sobre a desinformação a partir da intencionalidade do engano pode abrir mão para que perseguições políticas sejam conduzidas, na qual o acusado terá que provar de sua inocência, ante uma acusação de intencionalidade previamente conformada.

O enquadramento analítico sobre a ordem também é trazido por Lance Bennett e Steven Livingston (2018), ao proporem o conceito de ordem da desinformação, como mecanismo de perturbação da ordem democrática. Argumentam que tal ruptura da ordem é proveniente de um declínio da confiança dos cidadãos nas instituições que mina a credibilidade da informação oficial nas notícias e abre o público a fontes alternativas de informação. Apesar de concordar com parte do argumento sobre a crescente descrença sobre instituições epistêmicas, abordada por inúmeros pesquisadores (Moisés, 2005; Van de Walle, Six, 2014; Dahlgren, 2018; Albuquerque, Quinan, 2019; Oliveira, et al, 2020; Oliveira, 2020), a forma de construção do argumento dos autores recai sobre uma legitimação das fontes oficiais de notícia - ou seja, o jornalismo - e acusa atores exógenos (ou seja, o outro que não é jornalista, o outro que não é democrático, o outro que não conterrâneo, especialmente os "russos") como causa da ruptura de uma ordem informacional.

Portanto, a premissa de existência de uma ordem que está sendo corrompida deriva de um pensamento linear e funcionalista da comunicação, que entende que há um ordenamento do mundo como um ideal para a eficiência de uma comunicação direcionada. Tal perspectiva tem sido amplamente questionada no campo da comunicação desde a década de 1970, sobretudo na América Latina (Tufte, 1998), a partir de estudos críticos da recepção (Albuquerque, Tavares, 2020), que entendem que uma mensagem não se baseia em um modelo matemático linear do processo comunicativo. Jesus Martin Barbero, Nestor Garcia Canclini, Eliseo Verón, Renato Ortiz, José Marques de Mello, Luis Ramiro Beltrán, Paulo Freire, entre muitos outros pensadores latino-americanos contestaram tal perspectiva funcionalista da comunicação, trazendo para o pensamento comunicacional, a importância do reconhecimento das mediações e negociações do receptor nos processos comunicativos.

\footnotetext{
${ }^{1}$ No trabalho em questão, Wardle e Derakshan reconhecem que o receptor não é um agente passivo, mas limitam sua agência apenas na retransmissão da mensagem.
} 
Outros estudos tendem a ancorar suas análises, ainda na ordem da produção como matriz analítica para estabelecer formatos e linguagens próprias do engano, como busca de padrões textuais, como títulos sensacionalistas, ausência de fontes, entre outros. Contudo, dissimulação e apropriação de signos de instituições epistêmicas que são usados para validar aquela mensagem, que tem sido descrito como Fake Sciences (Oliveira et al, 2020), não são estruturas simples de serem identificadas, como constata Rietjens (2019), que afirma que neste processo o mascaramento torna a realidade invisível, a reembalagem esconde e disfarça a realidade, mudando sua aparência, e o deslumbramento reduz a certeza sobre a natureza do objeto. Trazendo discussões a partir do campo da psicologia, Rietjens traz o conceito de "deception" (traduzido literalmente como engano) para discutir as nuances em torno do conceito de desinformação. Para o autor, as operações do engano (deception) podem ser estruturadas de duas maneiras: dissimulação e simulação da realidade. A primeira tende a ocultar e dissimular a realidade a partir de três mecanismos: 1) mascarando (fazendo realidade invisível), (2) reembalagem (escondendo a realidade disfarçando-a e mudando sua aparência) ou (3) confusão por meio de 'deslumbramento' (reduzindo a certeza sobre a real natureza de qualquer coisa). Já a segunda, a simulação, tende a reforçar e evidenciar a informação falsa, a partir de três mecanismos: (1) imitar (copiar alguns aspectos para representar uma imitação aceitável), (2) inventar (mostrar outra realidade) e (3) armadilha (distraindo a atenção). Para o autor, enquanto simulação consiste em propor uma versão falsa da realidade, a dissimulação retém parte da realidade do alvo. Portanto, perceber as nuances de mascaramento, apropriação, disfarce, dissimulação é extremamente importante para uma melhor definição sobre o engano e a desinformação para além de uma construção a partir da intencionalidade da desinformação.

Uma outra vertente sobre o conceito tende a enquadrar a desinformação tendo a fonte como matriz analítica. Tais literaturas ancoram-se em valores de confiança e perícia de instituições epistêmicas, anteriormente discutidas, para propor desclassificações daquilo que não faz parte de seu próprio circuito. Geralmente associam a desinformação a fatores exógenos, como forças externas, estrangeiras, anti-democráticas ou anti-institucionais (Jamieson, 2018; Boyd-Barrett, 2019) que atacam estas instituições que se auto-legitimam como produtoras e disseminadoras de conhecimento, de informação de confiança e de verdade. Frequentemente estão associados a disputas sobre a produção de verdade e discursivamente são construídas a partir do argumento de que contestam e desautorizam a veracidade informacional das instituições legítimas a produzir informação de confiança.

Neste momento de pandemia, artigos de jornais frequentemente reafirmam a importância cívica da profissão de jornalista no mundo pandêmico, posicionando seus profissionais como figuras essenciais na linha de frente contra a desinformação. Por exemplo, o jornal Folha de São Paulo publicou um artigo de opinião de Sylvia Colombo (2020), intitulado "Jornalistas são essenciais em tempos de pandemia", afirmando que "esses tempos terríveis precisam de informações bem afiadas e do debate crítico oferecido pelo jornalismo profissional". Essa forma de se posicionar como bastião da verdade se contrapõe a outras formas de comunicação, isentando de sua própria responsabilidade na desacreditação não só da sua autoridade, mas também de outras autoridades epistêmicas, visto sua atuação no processo de midiatização de controvérsias científicas e nos ataques às universidades (Oliveira et al, 2020).

No entanto, de acordo com teorias da comunicação de massa que entendem a notícia como produto socialmente construído e consensuado a partir de expectativas sociais (Campos, 2009), é possível entender o jornalismo não como baluarte da verdade, mas 
como reflexo de políticas editoriais, e portanto, ecoam posicionamentos corporativos das empresas através de enquadramentos, silenciamentos, omissão, ênfase e demais recursos narrativos calcados em modelos anglo-americanos de produção de notícia que obscurecem vieses de noticiabilidade.

Quando buscamos traçar o conceito de desinformação trazendo para o campo científico, outros elementos são incorporados ao discurso de legitimação de si. Alguns autores a atribuem a falência das metanarrativas e a crise da ciência a um fracasso pósmoderno (Lyotard, 1998). Esse fracasso das metanarrativas e a pretensa universalidade do projeto iluminista provocou uma descrença sobre a ciência. Segundo Grenz (1997, p. 76), “Tornamos-nos não apenas cientes de uma pluralidade de histórias legitimadoras de conflitos, como entramos igualmente na era da morte da metanarrativa. $\mathrm{Na}$ era pós-moderna, todas as coisas são deslegitimadas". Esse abandono de metanarrativas e projetos universalizantes abriu campo para o metafísico provocando novas disputas para conhecimentos alternativos, como as chamadas pseudociências (Novaes, 2006). No entanto, o que é pseudociência? Poderia ser entendida como um mecanismo de autolegitimação enquanto produtor de verdade, desclassificando através de demarcações epistêmicas os conhecimentos/informações alternativas produzidas pelo "outro" como não-verdade? Como essas demarcações definem quais crenças são epistemicamente garantidas?

Assim como no conceito de desinformação, as definições sobre o que é pseudociência baseiam-se em torno da noção de falso e de intencionalidade. Tais demarcações têm uma longa discussão no campo da filosofia da ciência, que implicam não apenas a questão de métodos e procedimentos empíricos a partir de rigor e ética, mas diz respeito também a disputas inerentes ao próprio campo científico seja a partir de um programa de pesquisa (Lakatos 1970), um campo epistêmico (Mahner 2007), uma teoria (Popper 1962) ou problemas e questões científicas (Siitonen 1984). As complexidades sobre demarcações epistêmicas vão ao encontro do princípio de falseabilidade de Karl Popper (2004), em que se defende que as teorias que não oferecem possibilidade de serem refutadas por meio de análises, estudos, testes e experiências empíricas devem ser consideradas como mitos, ou não-ciência. Nesta perspectiva de falseabilidade, as teorias que já foram colocadas à prova de refutação estão passíveis de mudanças de caráter ao longo do tempo, à medida que o ser humano amplia seus conhecimentos e suas descobertas. Segundo a Enciclopédia Stanford de Filosofia ${ }^{2}$, a mutabilidade da ciência é um dos fatores que torna difícil a demarcação entre ciência e pseudociência. Derkson (1993) acrescenta que além da mutabilidade, outra dificuldade de demarcação entre ciência e pseudociência reside em sua característica heterogênea, o que pode ser entendida como própria do campo científico. Para Bourdieu, o campo científico é um espaço de jogo de uma luta concorrencial (Bourdieu, 1976). Ou seja, dentro das áreas do conhecimento há disputas em torno do monopólio da autoridade e legitimidade, de maneira autorizada e com autoridade. As demarcações entre ciência e pseudociência se inserem também nesta luta concorrencial pelo monopólio da autoridade em torno do domínio pelo conhecimento que transcendem definições em torno da verdade da ciência.

Por exemplo, Bhavisha P. Sheth e Vrinda S. Thaker (2014) compararam a pseudociência ao fenômeno da retratação científica, afirmando que trata-se de uma violação da ética e desonestidade. Carregado no discurso positivista de que a ciência é o único conhecimento possível, afirmam ainda que "o fenômeno da retratação científica é um

${ }^{2}$ https://plato.stanford.edu/entries/pseudo-science/ 
ato vergonhoso para a comunidade científica, mas uma necessidade para manter a pureza da ciência" (grifo nosso). No entanto, o que é uma ciência pura? Poderíamos demarcar de maneira dicotômica o campo científico pela sua pureza a partir da dimensão ética, tal como apontam os autores? Um exemplo recente, que nos permite pensar para além destas dicotomias simplistas, é o caso da revista Lancet, que publicou o estudo com base em dados de 96 mil pessoas internadas com Covid-19 em que mostrava que quem havia tomado hidroxicloroquina apresentava maior risco de arritmia e morte em comparação com pacientes que não usaram a medicação. Foram feitas denúncias e críticas da comunidade científica sobre os dados da pesquisa publicada no prestigiado periódico, fornecidos pela empresa norte-americana Surgisphere. Indagados, a empresa não aceitou transferir a base de dados de completa utilizada, argumentando que tratava-se de violação dos acordos éticos de confidencialidade com clientes, questão presente tanto na dimensão concorrencial de acesso aos dados por questões de segurança nacional, segredos comerciais, conservação, processo legal e privacidade, estabelecido pela Organização para a Cooperação e Desenvolvimento Econômico (OCDE), em seus Princípios e Diretrizes para Acesso a Dados de Pesquisa com Financiamento Público, como também em medidas protetivas em diferentes resoluções éticas para a garantia de anonimato dos participantes de pesquisa.

Para além dos impasses éticos em torno da abertura de confidencialidade dos participantes do estudo, as disputas a partir da circulação desta publicação transcenderam o circuito acadêmico, e a repercussão sobre os impasses abriram margem para o surgimento de narrativas alternativas e para que o estudo científico ganhasse também contornos políticos.

Após a repercussão na comunidade científica e na mídia, o estudo foi retratado pelos próprios autores, sem antes ganhar contornos políticos. No Brasil, Nise Yamaguchi, oncologista e imunologista defensora da hidroxicloroquina e integrante do gabinete de crise criado pelo presidente Jair Bolsonaro para pesquisas sobre covid-19, foi uma das críticas do estudo. Em suas declarações pró-cloroquina chegou a afirmar que a recusa em recomendar e divulgar o medicamento estaria ligada a "interesses escusos" de líderes empenhados em uma conspiração contra a vida em uma competição geopolítica entre grandes potências pela dominação do planeta (Sampaio, 2020) argumento recorrente e que ecoa facilmente não apenas entre teóricos da conspiração, mas também entre a própria comunidade científica perante uma corrida entre várias potências mundiais e da indústria farmacêutica em registrar pesquisas e inovações em tratamento e vacinas contra Covid-19 (Wallace, 2020; Rutschman, 2020, entre outros). Conforme demonstraram Ronaldo Araújo e Thaiane Oliveira (2020), a disputa informacional em redes sociais digitais sobre hidroxicloroquina tem sido protagonizada mais por aspectos políticos do que de saúde, em um processo de politização da ciência centrado em algumas figuras públicas, sobretudo políticos. A circulação de informações sobre o medicamento se desdobrou para além de um espectro pautado na intencionalidade. Não se tratavam de informações que tinham a intencionalidade de enganar, mas disputas de sentido complexas na circulação da informação no ambiente digital. Os sentidos variavam entre ataques e apoios a agentes políticos, pressão política para a adoção da medicação no sistema público de saúde, manifestações de descrenças sobre as instituições epistêmicas (sobretudo a mídia e a ciência) e teorias da conspiração, além da apropriação sobre figuras e instituições, jargões e produtos da ciência, como uma forma de reafirmação do viés de crença do usuário seja ela contra ou a favor do uso da cloroquina. Os autores apontam que valores da própria cultura científica, como autoridade e reconhecimento, vão ganhando novas camadas informacionais neste processo de disputa política, em um 
momento no qual as instituições epistêmicas estão em declínio de confiança junto à população.

Nesse complexo campo de disputas, as teorias da conspiração relacionadas à ciência vão ganhando espaço, causando grande preocupação para a comunidade científica (Knobel, Orsi, 2019). Entender o movimento antivacina, por exemplo, é relevante para a luta contra a Covid-19, já que alguns manifestantes afirmam que as vacinas "serão usadas para implantar microchips nas pessoas" ou mesmo "matarão milhões de pessoas" (Ball, 2020). Identificar os discursos em torno das teorias da conspiração neste momento de pandemia nos apresenta importantes pistas para refletir sobre nós mesmos, cientistas e membros das instituições científicas. A primeira delas é entender que os adeptos de teorias da conspiração refletem uma descrença sobre as instituições epistêmicas e manifestam sua percepção sobre conflitos de interesses dessas mesmas instituições que são recorrentemente midiatizados (Oliveira, 2020), sobretudo em relação à indústrias farmacêuticas e as disputas geopolíticas sobre o avanço de tratamentos contra Covid-19. Eles produzem narrativas alternativas mediante à sua frustração frente ao fracasso da ciência médica em fornecer respostas imediatas sobre a doença e como ela se espalhou pelo mundo. A incerteza sobre evidências científicas para pautar decisões políticas de orientação médica, de isolamento e distanciamento social ou a eficácia sobre o uso de máscara em espaços públicos, além de previsões econômicas e epidemiológicas com jargões e gráficos dominados apenas pelos pares, são um combustível potencial para as teorias da conspiração, que têm sido instrumentalizadas no campo político.

Quadros conceituais sobre a desinformação, ou desordem informacional, que persistem em enquadrar a partir da intencionalidade ou legitimar as instituições epistêmicas como fonte de confiança, pouco contribuem para desenvolver análises mais densas sobre estas disputas de informação nos ambientes digitais para traçar estratégias e políticas de ação para melhor lidar com a este problema que vem pautando discussões frente à pandemia. Se não é a intencionalidade ou a fonte que devem pautar a discussão sobre a desinformação, como conceituar esse fenômeno? Entendendo o processo comunicacional, um outro caminho possível de se enquadrar o fluxo comunicativo, é um olhar sobre a circulação. Para tanto, é importante entender quais têm sido as abordagens apontadas nas pesquisas científicas para enfrentamento à desinformação e as consequências sobre a recepção destas ações.

\section{TRÊS ABORDAGENS DEENFRENTAMENTO AO COMBATE À DESINFORMAÇÃO}

Três abordagens para o enfrentamento à desinformação têm sido recorrentes na literatura científica uma instrumental e classificatória sobre a verdade, através de ferramentas de checagem de fatos; uma normativa, devedora das teorias democráticas deliberativas, que defende que os cidadãos possuem competências para tomar decisões racionais a partir de suas próprias buscas por informação; e a esperança na educação, a partir de ações de letramento midiático e informacional. Discutiremos, portanto, algumas implicações, consequências e desafios para cada uma das abordagens, a partir de perspectivas multidisciplinares que nos ajudam a entender o fenômeno em sua complexidade.

A primeira e mais aclamada como solução para o enfrentamento à desinformação tem sido ferramentas de checagem de fatos, seja através de ações humanas ou através de Inteligência Artificial para identificação e classificação para verificação da informação. No entanto, muito tem se discutido sobre os critérios usados por essas ferramentas e agências para avaliar e classificar a informação, geralmente pouco transparentes e vai 
de encontro a preceitos democráticos no campo de teorias deliberativas (Lelo, 2020. Por exemplo, Afonso de Albuquerque (2020, em prelo) discute que, por trás da noção de que as ferramentas de checagem de fatos fornecem informações precisas fundamentais para permitir aos cidadãos tomar decisões conscientes, há vieses políticos no processo de seleção de verificação da informação. Argumenta ainda que no Brasil, tem se consolidado um ecossistema de arranjos complexos composto por uma rede diversificada e bem estruturada de agentes privados e organizações não governamentais. Nesta rede encontram-se veículos jornalísticos brasileiros que foram muito atuantes na derrocada das instituições no país, com apoio financeiro do Google News Initiative e do Facebook Journalism Project e da Associação Brasileira de jornalismo Investigativo, carregam consigo "a legitimação a priori das instituições tradicionais da democracia - aí incluída a mídia tradicional" (de Albuquerque, 2020, em prelo) como provedoras incontestáveis da verdade. Apesar de um contexto distinto, estes argumentos foram identificados em pesquisas que apontam que os usuários não possuem tanta confiança nas ferramentas de checagem de fatos (Brandtzaeg, Folstad, 2017). No contexto brasileiro, em uma pesquisa aplicada com 108 estudantes de graduação na Universidade Federal de Minas Gerais, Thales Lelo (2020) observou que a concordância em correções oferecidas por fact-checkers é também moderada pelo partidarismo dos respondentes.

Estudos também têm questionado a utilidade de iniciativas de verificação de fatos, bem como moderação de conteúdo (Lim, 2018; Marietta et al., 2015). Autores enquadram tais iniciativas como soluções fáceis (Bennet, Livingstone, 2018) e a entendem como uma obsessão com checar, etiquetar ou sinalizar notícias falsas, correndo o risco de superestimar o valor da avaliação crítica das fontes em detrimento do reconhecimento da existência de outras formas de narrativa sobre a humanidade (Andersen, Soe, 2020).

Além disso, pesquisas apontam que o alcance das informações corrigidas é menor do que a própria desinformação em si, podendo se espalhar com tanta eficácia que, mesmo quando corrigidas, permanecerão dentro do conjunto não verificado de conhecimento comum (Thaler, Shiffman, 2015). Ainda, o uso de escalas de verdade, que refutam apenas uma parte, tendem a enfraquecer a eficácia sobre a correção da informação e aumentam a probabilidade de deixar de acreditar em títulos verdadeiros, sobretudo quando atenuado por crenças preexistentes e ideologia dos participantes (Walter, et al, 2020).

As dinâmicas de circulação e de consumo também são pontuadas por pesquisas que identificaram, por exemplo, que tais ferramentas são utilizadas apenas quando confirmam atitudes anteriores e evitados quando contradizem os sistemas de crença dos participantes (Hameleers, et al, 2020). Apontam também que a circulação da desinformação não é linear e os rumores tendem a reverberar e ressurgir muitas vezes após a publicação inicial, enquanto as notícias factuais não surgem repetidamente (Shin, et al, 2018).

Como um outro polo de discussão, com base nas teorias deliberativas, uma segunda abordagem argumenta que os sujeitos possuem as capacidades necessárias para a tomada de decisão sobre o consumo informacional e que a questão deva ser endereçada sobre a elaboração de uma ética da informação e da mídia Tendo como premissa teorias democráticas e deliberativas, tal abordagem defende que os cidadão possuem competências para tomarem decisões racionais e bem informadas, promovendo o progresso dos sistemas políticos vigentes (Lelo, 2020). Portanto, neste tipo de abordagem, e mediante a profusão de informações, entende-se que é necessário partir de valores como reconhecimento, liberdades e confiança, próprios 
das teorias deliberativas, combinada à elaboração de estratégias normativas sobre os processos comunicativos. Ideais e valores democráticos (Honneth, 2009), neste tipo de abordagem, podem ser negociados e diferentes opiniões se encontram para chegar a acordos mútuos ou apenas coexistir como uma democracia participativa (Bechmann,, 2020). No campo científico, tais estratégias normativas trazem uma agenda utilitarista sobre uma ciência aberta e democrática, em torno de discursos de aceleração, eficiência, transparência e possibilidade de reprodutibilidade para restaurar uma confiança em declínio (Oliveira, et al, 2020). A 'ocupação' dos espaços digitais para disputar sentidos em um ambiente profícuo para a circulação de desinformação é colocada como uma ação necessária e urgente para cientistas e divulgadores de ciência, na certeza de que os sujeitos passarão a confiar mais na ciência se ela ganhar visibilidade nas plataformas de redes sociais.

No entanto, as dinâmicas de circulação da informação nos apontam para alguns limites desse tipo de abordagem, ignorando lógicas próprias das redes sociais digitais, por onde seu conteúdo circula. As plataformas de mídias sociais, a partir de suas mediações algorítmicas, segmentam seus gostos a partir de lógicas mercadológicas próprias das redes sociais digitais. Pesquisas já vêm apontando a relevância do algoritmo das plataformas de mídias sociais para o aumento de visibilidade de teorias da conspiração relacionadas à ciência (Oliveira et al, 2020; Oliveira, 2020; Machado et al, 2020). A lógica de big data e todas as dinâmicas derivadas dos avanços tecnológicos em torno da algoritmização pela experiência do usuário, próprios do sistema de consumo personalizado de informação, têm permitido que a informação e a desinformação avancem a partir de escolhas, hábitos e preferência de consumo de usuários. "Bolhas informacionais" e "câmaras de ecos", ainda que sejam apenas metáforas frente à dinâmicas de circulação em redes sociais digitais, são utilizadas para compreender o fluxo informacional nestes ambientes que limitam o acesso a um amplo espectro da informação que possa ir de encontro com outras visões de mundo do usuário. Pesquisas apontam que efeitos de câmara de eco contribuem para a polarização de opiniões, viralidade e disseminação de desinformação, formando um movimento inicial para a difusão (Törnberg, 2018, Burns, 2019). No entanto, para além da visão tecnicista que culpa apenas infraestruturas das plataformas digitais, há outros fatores que corroboram para um sentimento de descrença sobre as instituições epistêmicas. Conforme aponta Tatiana Dourado (2020), dia após dia os sujeitos estão acompanhando, em diferentes veículos e canais de comunicação - e não apenas nas mídias sociais - a ataques sistemáticos à imprensa, às universidades, às instituições públicas e à democracia em forma de discursos intervencionistas, intolerantes, incivis e de ódio. Portanto, a descrença generalizada sobre instituições epistêmicas transcende metáforas tecnicistas - muitas vezes pouco explicativas - das bolhas informacionais e se manifestam em diferentes canais de comunicação, entre elas a própria mídia tradicional, historicamente influente sobre a esfera pública brasileira.

Como uma alternativa aos modelos classificatórios sobre a verdade, que vão de encontro às teorias democráticas, investimentos em ações de letramento midiático e informacional são apontadas como antídoto para desinformação e para as notícias falsas (Charleaux, 2018). Segundo a Unesco (2016), "para combater as Fake News, é preciso oferecer treinamento dos sujeitos para se defenderem das culturas dominantes e criar seus próprios efeitos contrários a elas". Em outro relatório (2018), a Unesco afirmou que "o empoderamento de pessoas por meio da Alfabetização Midiática e Informacional (MIL) é um pré-requisito importante para promover o acesso igualitário à informação e ao conhecimento e os sistemas de mídia e informação livres, independentes e plurais". É comum o entendimento do letramento midiático e informacional como capacidade de acessar, entender e criar comunicações em 
diversos contextos (Buckingham, 2005), de acessar, analisar e efetivamente desenvolver habilidades de pensamento crítico e de aprendizagem sobre as mídias para a implementação da cidadania ativa (Livingstone, 2002). Na maior parte dessas ações, as atividades de letramento midiático e informacional são desenvolvidas nas escolas. No entanto, a forma como as políticas de letramento midiático é estabelecida, de um lado retira do estado o papel de investimento em estruturas educacionais multidisciplinares e qualificadas, atribuindo aos professores a responsabilidade e $o$ domínio de reflexão sobre práticas de consumo e produção informacional atuais, dos quais muitos não têm conhecimento. É exigida da escola esse domínio sobre novas tecnologias, novas linguagens midiáticas e a inclusão, por exemplo, de atividades de Inteligência Artificial, sem esses mesmos profissionais terem tido contato com uma reflexão crítica e analítica sobre essas novas práticas derivadas da experiência digital.

Por outro lado, como vem sendo discutido por pesquisadores, como Danah Boyd (2017), a crítica sobre a mídia tradicional é um dos impulsos para um processo de descrença generalizada sobre as instituições disseminadoras de informação na atualidade. Porém, mais do que isso, algumas pesquisas apontam que as pessoas compartilham porque a informação vai ao encontro de suas crenças e confirmam sua opinião (Pennycook, 2020 - preprint). Apontam ainda que a necessidade de se sentir pertencido a um grupo social e o medo de se sentir "de fora" foram sentimentos associados ao compartilhamento de notícias falsas (Talware, 2019). Mostram também que as pessoas se sentem portadores de uma notícia privilegiada e compartilham para aumentar o capital social na sua rede de relações (Grabner-Krauter, Bitter, 2013). Ou seja, não se trata de falta de educação sobre a informação, visto que as pessoas optam conscientemente por compartilhar mesmo sabendo que o conteúdo pode não ser "verdadeiro".

Então como enfrentar a desinformação científica, levando em consideração os limites dos três tipos de abordagens apresentadas anteriormente? Algumas pistas multidisciplinares nos trazem importantes resultados sobre a recepção de ações de enfrentamento à desinformação. Em uma pesquisa no qual os participantes foram agrupados em pró-vacina e duvidosos sobre a vacinação, evidenciou-se que o envolvimento modera o processamento de informações, a partir da comparação entre grupos pró e duvidosos sobre vacinação (Shen, Zhou, 2020). Em outra pesquisa (Donovan, Rapp, 2020), os participantes que tiveram a oportunidade de procurar informações tinham menos probabilidade de reproduzir informações imprecisas e mais chances de produzir respostas corretas, em comparação com o desempenho dos participantes que não tinham permissão para pesquisar. Também testaram se os avisos sobre informações potencialmente imprecisas incentivariam as pesquisas e informariam as respostas. Enquanto os avisos aumentavam a busca, não foram observadas reduções adicionais nas reproduções imprecisas.

Pesquisas ainda apontaram que refutações são mais eficazes que as advertências e os apelos à coerência, que por sua vez, superam a verificação de fatos e os apelos à credibilidade (Walter, 2018). As refutações devem ser diretas, sucintas e evitar enfatizar informações erradas. Os comunicadores devem considerar emparelhar evidências científicas com histórias que falem e estimulem a reflexão sobre crenças e valores do público (Steffens, et al, 2019).

Apesar de retratações e verificações de fato terem um alcance menor, quando o participante reflete sobre as causas de suas crenças equivocadas, há uma maior possibilidade de revisá-las. Os resultados mostraram que avaliar a crença em uma causa-alvo antes de sua retração tornou a correção mais eficaz. (Ithisuphalap, et al, 2020). Tal pesquisa vai ao encontro de Nathan Walter e Sheila Murphy (2018) ao sugerir 
que se a informação for retratada sem fornecer uma explicação alternativa, a compreensão das pessoas sobre um tópico pode não parecer coerente, levando-as a negar as novas informações e a restabelecer as crenças que existiam antes da retratação. Para enfrentar efetivamente a desinformação, as mensagens devem fornecer uma explicação coerente que descreva o que realmente aconteceu e por que aconteceu. Pesquisas apontam também que enfatizar o erro, tenderá que a pessoa se lembre mais da informação equivocada do que a correção e mostram que contextos culturais diferentes podem ser importantes fatores sobre a percepção de desinformação (Xu, et al, 2020). Torna-se, portanto, necessário entender o contexto no qual as visões de mundo e a descrença são sentimentos recorrentes nas abordagens para o enfrentamento à desinformação.

\section{O CONTEXTO DA DESINFORMAÇÃO E DA DESCRENÇA SOBRE AS INSTITUIÇÕES EPISTÊMICAS}

A pandemia de Covid-19 gerou uma crise mundial sem precedentes. Além dos resultados econômicos e sociais da crise global de saúde, o Brasil tem enfrentado também uma crise institucional e uma grave política interna, que vem se alastrando pelo menos desde 2014, quando os questionamentos sobre as instituições democráticas passaram a ser recorrentes no debate público e na agenda midiática dos principais veículos de jornalismo de grande circulação do país. Desde então, uma série de acontecimentos políticos, amplamente midiatizados, foi enfraquecendo as instituições tradicionais da democracia, sob uma agenda de combate à corrupção (Gagliardi, Albuquerque, 2020) e aumentando a descrença e a desconfiança na percepção pública sobre estas organizações balizadoras da sociedade.

Estas instituições tradicionais da democracia foram fundadas em "sistemas de peritos" a partir de conhecimentos altamente especializados que garantem a confiança do cidadão no funcionamento social e exercício de papéis destas organizações como um exercício de "fé" (Giddens, 1991). Dentre estas, as instituições epistêmicas - foco central desta discussão - são aquelas que produzem ou disseminam conhecimento, consolidadas em torno de um gênero específico de perícia e como reivindicadoras da razão. Consolidadas em torno de métodos e formatos que garantem sua autoproteção e auto-preservação contínuas, estas instituições epistêmicas se autoinstituem como promotoras da verdade. No caso das ciências, o "puro método" impulsiona que todas as outras formas substantivas de "conhecimentos" estejam em princípio abertas a serem descartadas (Giddens, 1991, p. 155). No jornalismo, os formatos do modelo anglo-americano de objetividade, imparcialidade e neutralidade garantem que as políticas editoriais e posicionamentos políticos e ideológicos sejam transmitidos como um compromisso com a verdade (Amado, Waisbord, 2015; Tavares, 2019). Princípios de neutralidade, crença na objetividade, ética pública, compromisso com a "verdade" pelo bem da sociedade e adoção de normas, formatos e métodos específicos regem tanto o "paradigma da ciência" quanto o "paradigma do jornalismo", levando a uma supervalorização da razão e garantindo que estas instituições epistêmicas sejam porta-vozes da sociedade, acima de quaisquer tipos de disputas políticas, o que não se consolida na prática.

Apesar de ter se consolidado como uma comunidade de grande prestígio e credibilidade dentre as instituições epistêmicas, durante o progresso acelerado de desenvolvimento tecnológico e industrial (Weingart, Guenther, 2016), atualmente a ciência tem vivido uma série de crises e questionamentos, decorrentes dos mais 
diferentes fatores. Pesquisas como a desenvolvida pela 3M - Science Applied to Life3, mostra um crescimento do ceticismo relacionado à ciência no Brasil e no mundo. Apesar do interesse sobre ciência no Brasil ser maior do que a média mundial, conforme aponta a pesquisa realizada pelo Centro de Gestão e Estudos Estratégicos $\left(\mathrm{CGEE}^{4}\right)$, as pessoas acreditam na informação científica apenas quando veem suas crenças confirmadas, sobretudo em relação a assuntos controversos, que geram grande circulação de desinformação. Este é um problema enraizado em um problema de confiança sobre instituições epistêmicas diante de um fenômeno em que crenças e experiências individuais (Van Zoonen, 2012) são indicadores de pertencimentos sociais, e que podem entrar em conflito com o conhecimento estabelecido pelos canais epistêmicos através da dúvida, da midiatização de controvérsias científicas e politização da ciência (Kahan, et al, 2012; Oliveira et al, 2020).

Se por um lado, existe uma urgência de se comunicar a ciência para a sociedade para restabelecer a confiança junto à população, por outro lado há um declínio de confiança também sobre os espaços de produção e difusão de informação, como os jornais e a mídia tradicional (Braten et al, 2011), inclusive como projeto político de diferentes líderes e representantes governamentais mundiais, como parte de uma agenda conservadora. Segundo Almeida (2017), esta agenda conservadora que se desponta em vários países se estrutura a partir de valores morais de regulação jurídica e controle repressivo a partir do aparelhamento de instituições de vigilância e punitivas e intolerância social. No entanto, apesar dessa atuação do Estado nas formas de controle e regulação sobre a sociedade, a sua presença na economia vai gradualmente diminuindo à medida que se fortalece agendas neoliberais sobre a gestão de investimentos do estado em instituições provedoras de conhecimento. Por fim, esta agenda conservadora, que decorre a partir de lógicas liberais sobre os indivíduos, se encontram com dinâmicas de personalização do consumo própria das redes sociais digitais, fazendo emergir atores de influência na propagação de desinformação (Karlova, Ficher, 2013), frente ao declínio de confiança da população nas instituições democráticas e na instauração da dúvida sobre a informação que se recebe por diferentes canais alternativos. E isso tem sido a estratégia central de algumas lideranças políticas mundiais, aproveitando-se de um sentimento de desconfiança sobre as instituições anteriormente preparada no terreno político, capitaneada por setores legisladores e pela própria imprensa (Albuquerque, 2019; 2020).

\section{UMA AGENDA DE GUERRA HÍBRIDA SOBRE A INFORMAÇÃO}

Segundo o instituto Poynter, organização de pesquisa sem fins lucrativos localizada nos Estados Unidos e com financiamento de gigantes da web, como Google e Facebook, entre outras ${ }^{5}$, inúmeras ações têm sido feitas em vários países para combater a desinformação. Desde força-tarefa e ações de letramento midiático (Bélgica, Holanda e Nigéria) a multas, cortes de acesso à internet (Índia) e criminalização e prisões (Arábia Saudita e China). No Brasil, publicar uma fake news é passível de multa (JN, G1, 2019) e tem havido movimentos de esforços para controle sobre a informação/desinformação. Atualmente tramitam 41 projetos de lei na câmara dos deputados, dos quais 22 estão relacionados à Ciência, Tecnologia e Comunicação.

\footnotetext{
3 https://news.3m.com/English/press-releases/press-releases-details/2019/World-Wants-Science-to-Solve-GlobalProblems-Even-as-Skepticism-Grows/default.aspx

4 https://www.cgee.org.br/documents/10195/734063/CGEE_resumoexecutivo_Percepcao_pub_CT.pdf

5 https://www.poynter.org/major-funders/
} 
Entre os 41 projetos, propõe-se o estabelecimento de que disseminar notícias falsas é passível de multa e até 8 anos de prisão. Conforme apontam Theófilo Rodrigues, Luana Bonone e Renata Milelli (2020), a maior parte dos projetos de lei apresentados no Congresso Nacional propõe a mudança deste dispositivo da Lei 12.965/2014. Os autores apontam que "Ao contrário do que possa parecer, não é violando a privacidade e aumentando o poder de moderação das plataformas sobre o debate público, gerando riscos potenciais à liberdade de expressão, que o fenômeno atual da desinformação será combatido (Rodrigues, Bonone, Milelli, 2020, p. 48). Segundo a Agência Pública (2018), um dos projetos mais radicais apresentados para combater as fake News é de autoria do deputado Francisco Floriano (DEM-RJ), o PL 9533/2018, que insere a participação na produção e divulgação de notícias falsas à Lei ${ }^{\circ} 7.170 / 1983$, que define os crimes contra a segurança nacional, a ordem política e social.

Recentemente, a Comissão Parlamentar Mista de Inquérito (CPMI) composta para investigar notícias falsas nas eleições de 2018, após denúncias de existência de um "gabinete do ódio" dentro do próprio Planalto, está voltada também para identificar "os patrocinadores dessas pessoas que se utilizam de perfis falsos para depreciar as instituições, a família e atentar contra a vida, com falsas informações sobre o coronavírus", segundo o Angelo Coronel (PSD-BA), presidente da comissão (Exame, 2020). Esta ampliação da atuação da CPMI aconteceu após ataques virtuais contra jornalistas científicos e divulgadores de ciência que se opunham às declarações do presidente Jair Bolsonaro em sites de redes sociais, que vão de encontro às evidências científicas (Hafiz, Vaz, Revadam, 2020). Antes mesmo da pandemia declarada pela Organização Mundial de Saúde (OMS) em março de 2020, a CPMI já havia aprovado pedidos para promover audiência com representantes da OMS e interrogatórios a pessoas ligadas ao movimento antivacina e a sites com recomendações médicas falsas. Apesar de figurar nas discussões mais recentes sobre propostas de regulamentação sobre a circulação de desinformação, as disputas sobre a informação e desinformação científica são tangenciadas do debate legislativo. Tais discussões desdobram-se, sobretudo, a partir de uma preocupação no campo da comunicação e os processos produtivos de circulação da informação, a partir de uma premissa pautada numa agenda de guerra para combater a desinformação. Portanto, torna-se necessário entender estas disputas no campo da regulamentação sobre a informação, e seus debates travados na identificação e criminalização sobre a produção e disseminação de desinformação a partir de um entendimento sobre a intencionalidade de quem a produz.

No Senado, o Projeto de Lei das Fake News (PL 2.630/2020), aprovado em 30 de junho de 2020, prevê multas e penalidades criminais para quem divulga e compartilha notícias falsas e pressiona plataformas digitais a adotar medidas mais rígidas contra ataques cibernéticos, desinformação, notícias falsas e incitação ao ódio. Nesta PL, normas e regras foram estipuladas para coibir contas falsas e robôs, facilitar o rastreamento do envio de mensagens em massa e garantir a exclusão imediata de conteúdos racistas ou que ameacem crianças e adolescentes, além de regras para as contas institucionais de autoridades, como o presidente da República, e prevê punições para as plataformas que descumprirem as novas normas. $O$ texto aprovado também obriga as plataformas a excluírem as contas falsas, criadas ou usadas "com o propósito de assumir ou simular identidade de terceiros para enganar o público" (Haje, 2020). No caso de plataformas de mensagens instantâneas, como Whatsapp e Telegram, é exigido que os provedores mantenham à disposição do Judiciário, por um período de três meses, os registros dos encaminhamentos das mensagens em massa, entre elas a identificação dos remetentes, a data e horário dos envios das mensagens e o número total dos destinatários que as receberam. 
Já na Câmara dos Deputados, há um projeto em andamento para construir um texto "melhor" do que o aprovado pelo Senado, segundo o presidente da Câmara, Rodrigo Maia. Nas palavras de Maia, "Eu tenho certeza que os parlamentares, junto com a sociedade, vão conseguir chegar a um texto que garanta as liberdades de cada cidadão, mas que organize o tema para que aqueles que usam (as redes sociais) de forma indevida possam ter a sua punição" (Luiz, 2020). Depois dos ataques contra o youtuber Felipe Neto, que se posicionou contra o governo em seus vídeos, Rodrigo Maia, disse que queria pressionar para acelerar a votação do Projeto de Lei (Xavier, 2020), o convidando para discutir o tema na Câmara, causando tensões de aliados do governo em nome da liberdade de expressão, como aponta o requerimento no qual assinam Quatro deputados da base do governo: "Toda a ideia do projeto das Fake News parece querer criminalizar opiniões, e o pior, apenas opiniões conservadoras" (Moura, 2020)

A pressão sobre as plataformas digitais também vem acontecendo no Supremo Tribunal Federal (STF). O ministro do STF, Alexandre de Moraes, ordenou o pagamento de multas pelo Facebook, caso a plataforma não bloqueasse perfis falsos relacionados ao Bolsonaro identificados pela CPMI. Ao negar a determinação do Facebook, que argumentava que os perfis são de fora do país, Alexandre de Moraes, aumentou a multa de 20 mil para 100 mil reais (Galf, Mattoso, Seto, 2020). Dois dias depois da decisão, o diretor do Facebook concedeu entrevista ao Fantástico, programa semanal da TV Globo, após retirar os perfis vinculados ao Bolsonaro, acusados de divulgar notícias falsas e criar perfis falsos para divulgar desinformação e discurso de ódio.

Após esta suspensão de contas, Bolsonaro acionou o Supremo contra a medida, alegando que este tipo de ação é uma ameaça à liberdade de expressão. Em ação direta de inconstitucionalidade assinada junto do Advogado-Geral da União (AGU), José Levi Mello do Amaral Júnior, Bolsonaro alegou que medidas como inconstitucionais e uma ameaça à democracia a suspensão de perfis de blogueiros e empresários bolsonaristas como do ex-deputado federal Roberto Jefferson (PTB), dos empresários Luciano Hang e Otávio Fakhoury, e dos apoiadores do governo Allan dos Santos, Sara Giromini (Sara Winter), entre outros ${ }^{6}$. Em seguida, o presidente da Câmara, Rodrigo Maia enviou ao Supremo Tribunal Federal (STF) uma manifestação em que pede a rejeição da ação movida pelo presidente Jair Bolsonaro contra o bloqueio de redes sociais de bolsonaristas, argumentando que ação direta de inconstitucionalidade, instrumento utilizado pelo Bolsonaro, não é o meio processual adequado para tratar o assunto.

Diante deste cenário de disputas entre os Três Poderes, legislativo, executivos e judiciários, tem sido recorrente a afirmação de que estamos vivendo uma guerra híbrida (Van Puyvelde, 2015), nos discursos midiáticos, e também acadêmicos, sobretudo filiados a institutos das forças armadas (Colom, 2012; Piccolli, Machado, Monteiro, 2016; Leal, 2015; 2016). De acordo com esta abordagem, a desinformação tem sido utilizada como arma política numa guerra híbrida em que fake news, entre outras ações como lawfare e intervenção eleitoral externa entre outras, são utilizadas como métodos convencionais e não convencionais, com atuação estatal e não-estatal no emprego de táticas para desestruturação política e econômica. Conforme discute Hugo Miguel Moutinho Fernandes (2016), o termo guerra híbrida aparece em 2005, podendo remontar aos atentados de 11 de setembro de 2001, e foi posteriormente usado para descrever a estratégia utilizada pelo Hezbollah na segunda guerra do Líbano de 2006. É entendida como um conjunto de técnicas, entre elas informacionais,

${ }^{6}$ https://istoe.com.br/twitter-bloqueia-contas-de-luciano-hang-allan-dos-santos-sara-winter-e-mais-13/ 
com o objetivo de desestabilizar os governos oponentes e as suas instituições, esvaziando o poder e a atuação política das instituições democráticas.

No entanto, a forma como tais projetos mencionados acima tratam o tema de regulamentação e criminalização da desinformação levando em consideração a intencionalidade dos sujeitos na produção da "desordem informacional" tem sido travada a partir de uma agenda de guerra, voltada para emplacar novos regimes políticos não mais regidos pela ordenação institucional e sim por uma urgência de combate que suspende qualquer racionalidade e permite medidas autoritárias e antidemocráticas em prol de enfrentar um inimigo que mal somos capazes de conceituar.

\section{CONSIDERAÇÕES FINAIS}

Em um esforço para conceituar a desinformação, foi necessário, neste momento, entender um conjunto de problemáticas e implicações sobre as disputas sobre a informação científica em diferentes esferas. Quando as próprias lideranças políticas são apoiadoras e protagonistas nas mais diversas formas de dinâmicas de circulação da desinformação, e vão de encontro à informações provenientes de fontes de instituições científicas, torna difícil o cidadão diferenciar o que é confiável ou não. Portanto, pensar a desinformação requer um esforço analítico que vai além de categorias estanques que tendem a simplificar a informação em torno de definições dicotômicas e maniqueístas acerca da verdade, de suas fontes de confiança ou da intencionalidade dos sujeitos. Portanto, apesar de usar o conceito de desinformação neste trabalho, reconhecemos a importância de aprofundar novos quadros analíticos que possam dar conta das disputas sobre a informação mediante a um cenário no qual a desconfiança sobre as instituições epistêmicas tem se tornado um projeto político de lideranças mundiais. Diante de um cenário de disputas políticas em torno da regulação sobre a desinformação e fake news, é necessário pensar na definição de desinformação para além da intencionalidade e legitimação de instituições epistêmicas. Levando em consideração a literatura aqui acionada, e as dinâmicas sobre sistemas de crença no processo de circulação da desinformação, é necessário definir o conceito para além da ordem da produção, mas compreendendo a complexa teia na circulação de sentidos sobre a desinformação. Tanto a ordem da desinformação (Bennet, Livingston, 2019), quanto a desordem informacional (Wardle, Derakhshan, 2017) partem de uma noção de ruptura de um ordenamento no processo de circulação de informações. Portanto, a circulação é a chave analítica necessária para uma melhor definição do conceito, levando em consideração os polos de produção, distribuição e recepção a partir de suas práticas e produção de sentidos mediados. Entendemos aqui a desinformação derivada de práticas sociais - enquanto parte de um fenômeno cultural mais amplo - no qual os sentidos são disputados para interesses próprios. Examinar a dinâmica da circulação da desinformação e suas disputas de sentido permite um olhar mais próximo para entender como as pessoas produzem, encontram, interpretam, conformam e confrontam as informações e as consequências que essas práticas têm para a produção de conhecimento compartilhado.

Em meio a disputas de informação e de narrativas no cenário político de diversos países, a pandemia de coronavírus tem sido um desafio para as frágeis democracias do mundo ocidental, seja através de medidas autoritárias de governos conservadores ou mesmo a abertura de precedentes para um recrudescimento sobre o controle da informação. Esta agenda de combate à desinformação tem se intensificado a cada dia e propostas e ações anti-democráticas que passam a ser naturalizadas e entendidas 
como um mal necessário em tempos de guerra não se limitam apenas às esferas políticas e legisladoras. Da mesma forma, quando a fonte de confiança é o centro do conceito, legitima-se instituições epistêmicas como produtoras de uma verdade absoluta, que por sua vez, deslegitima tudo aquilo que não vai ao seu encontro, outra grande ameaça à nossa democracia. Neste cenário, cabe a nós cientistas, sobretudo das humanidades, em entender e desvelar como essas agendas sobre a informação têm se desdobrado, buscando discutir as implicações sobre medidas que estão sendo disseminadas como soluções urgentes e necessárias hoje.

\section{REFERÊNCIAS}

AGÊNCIA PÚBLICA. 20 projetos de lei no Congresso pretendem criminalizar fake news. Agência Pública, 11 de maio de 2018. Disponível em:

https://apublica.org/2018/05/20-projetos-de-lei-no-congresso-pretendem-criminalizarfake-news/. Acesso em: 2020.

ALBUQUERQUE, Afonso de; TAVARES, Camilla Quesada. Corporatism, fractionalization and state interventionism: the development of communication studies in Brazil. Publizistik, p. 1-18, 2020.

ALBUQUERQUE, Afonso. Quem vigia os vigias?: o combate às fake news na pósdemocracia. In: COSTA, M. Qual o caminho do Brasil?: instituições, cultura e política no século XXI. Rio de Janeiro: Editora Appris, 2021. No prelo.

ALBUQUERQUE, Afonso. O discurso das fake news e sua implicação comunicacional na política e na ciência. RECIIS, v. 14, p. 184-198, 2020.

ALBUQUERQUE, Afonso; QUINAN, Rodrigo. Crise epistemológica e teorias da conspiração: o discurso anti-ciência do canal "Professor Terra Plana". Revista Mídia e Cotidiano, v. 13, n. 3, p. 83-104. 2019.

ALMEIDA, Ronaldo de. A onda quebrada-evangélicos e conservadorismo. Cadernos Pagu, n. 50, 2017.

AMADO, Adriana; WAISBORD, Silvio. Divided we stand: Blurred boundaries in Argentine journalism. In: BOUNDARIES of Journalism. Routledge, 2015. p. 51-66.

ANDERSEN, Jack; SØE, Sille Obelitz. Communicative actions we live by: the problem with fact-checking, tagging or flagging fake news-the case of Facebook. European Journal of Communication, v. 35, n. 2, p. 126-139, 2020.

ARAUJO, Ronaldo Ferreira; DE OLIVEIRA, Thaiane Moreira. Desinformação e mensagens sobre a hidroxicloroquina no Twitter: da pressão política à disputa científica. Atoz, v. 9, n. 2, p. 196-205, 2020.

BALL, P. Anti-vaccine movement could undermine efforts to end coronavirus pandemic, researchers warn. Nature, 2020.

BECHMANN, Anja. Tackling disinformation and infodemics demands media policy changes. Digital Journalism, p. 1-9, 2020. 
BENNET, Lance; LIVINGSTON, Steven. The disinformation order: Disruptive communication and the decline of democratic institutions. European Journal of Communication, v. 33, n. 2, 2018.

BOURDIEU, Pierre. O campo científico. In: ORTIZ, Renato. Sociologia. São Paulo: Editora Ática, 1976.

BOYD, Danah. You think you want media literacy... do you?. Medium, 2017. Disponível em: https://points.datasociety.net/did-media-literacy-backfire-7418c084d88d. Acesso em: 2020.

BOYD-BARRETT, Oliver. Fake news and 'RussiaGate'discourses: Propaganda in the post-truth era. Journalism, v. 20, n. 1, p. 87-91, 2019.

BRANDTZAEG, Petter Bae; FØLSTAD, Asbjørn. Trust and distrust in online factchecking services. Communications of the ACM, v. 60, n. 9, p. 65-71, 2017.

BRÅTEN, Ivar et al. The role of epistemic beliefs in the comprehension of multiple expository texts: Toward an integrated model. Educational Psychologist, v. 46, n. 1, p. 48-70, 2011.

BRUNS, Axel. Echo chamber?: what echo chamber?: reviewing the evidence. Biennial Future of Journalism Conference (FOJ17), 2017.

BUCKINGHAM, David. Media education: literacy, learning and contemporany culture. Combridge: Polity Press, 2005.

CAMPOS, Anabela. Está nos media. será mesmo notícia? ou obra deles?. Única (Expresso), v. 29, p. 36-42, 2009.

CASTRO, Gabriel Arruda. Dez monografias incomuns bancadas com dinheiro público. Gazeta do Povo, Curitiba, 13 jun. 2017. Disponível em:

https://www.gazetadopovo.com.br/educacao/dez-monografias-incomuns-bancadascom-dinheiro-publico-a8q52qvze7pygr8qavfieakyl. Acesso em: 2020.

CATRACA LIVRE. Em 18 horas, NY contabiliza 30 casos de intoxicação depois da fala de Trump, Catraca Livre, 26 abr. 2020. Disponível em:

https://catracalivre.com.br/saude-bem-estar/em-18-horas-ny-contabiliza-30-casos-deintoxicacao-depois-da-fala-de-trump/. Acesso em: 2020.

CHARLEAUX, João Paulo. A educação midiática como antídoto contra notícias falsas. Nexo, 19 nov. 2018. Disponível em:

https://www.nexojornal.com.br/entrevista/2018/11/17/A-educa\%C3\%A7\%C3\%A30-

midi\%C3\%A1tica-como-ant\%C3\%ADdoto-contra-not\%C3\%ADcias-falsas. Acesso em: 2020.

COLOM, Guillem. Vigencia y limitaciones de la guerra híbrida. Revista Científica General José María Córdova, v. 10, n. 10, p. 77-90, 2012.

COLOMBO, Silvia. Jornalistas são essenciais em tempos de pandemia. Folha de São Paulo, Opinião, 03 mai. 2020. Disponível em:

https://www1.folha.uol.com.br/colunas/sylvia-colombo/2020/05/jornalistas-saoessenciais-em-tempos-de-pandemia.shtml. Acesso em: 2020. 
COSTA, Camila. Neurocientista defende universidades geridas como empresas: 'É preciso demitir quem não produz'. BBC Brasil, 30 de maio 2016. Disponível em: https://www.bbc.com/portuguese/brasil-36365112. Acesso em: 2020.

DAHLGREN, Peter. Media, knowledge and trust: The deepening epistemic crisis of democracy. Javnost-The Public, v. 25, n. 1-2, p. 20-27, 2018.

DAVEY, Melissa. Covid-19 study on hydroxychloroquine use questioned by 120 researchers and medical professionals. The Guardian, 29 maio 2020. Disponível em: https:/www.theguardian.com/world/2020/may/29/covid-19-surgispherehydroxychloroquine-study-lancet-coronavirus-who-questioned-by-researchersmedical-professionals. Acesso em: 2020.

DERKSEN, Anthony A. The seven sins of pseudo-science. Journal for General Philosophy of Science, v. 24, n. 1, p. 17-42, 1993.

DONOVAN, Amalia M.; RAPP, David N. Look it up: online search reduces the problematic effects of exposures to inaccuracies. Memory \& Cognition, 2020.

DOURADO, Tatiana Maria Silva Galvão. Fake news na eleição presidencial de 2018 no Brasil. 2020. 308 f. Tese (Doutorado). Programa de Pós-Graduação em Comunicação e Culturas Contemporâneas, Universidade Federal da Bahia, Salvador, 2020.

EXAME. Prorrogação da CPI das Fake News é aprovada com foco na pandemia. Exame, 04 abr. 2020. Disponível em: https://exame.com/brasil/prorrogacao-da-cpidas-fake-news-e-aprovada-com-foco-na-pandemia/. Acesso em: 2020.

FALLIS, Don. What is disinformation?. Library Trends, v. 63, n. 3, p. 401-426, 2015.

GAGLIARDI, Juliana. La elección de 2018 y la gran prensa brasileña. Revista Política Latinoamericana, n. 7, 2018.

GALF, R.; MATTTOSO, C.; SETO, G. Decisão de Moraes contra perfis de bolsonaristas extrapola jurisdição e abre precedente para conflitos. Folha de São Paulo, 31 jul. 2020. Disponível em: https://www1.folha.uol.com.br/poder/2020/07/decisao-de-moraescontra-perfis-de-bolsonaristas-extrapola-jurisdicao-e-abre-precedente-paraconflitos.shtml. Acesso em: 2020.

GIDDENS, Anthony. As conseqüências da modernidade. São Paulo: Unesp, 1991.

GIRARDI, Juliana. Estudo sobre cloroquina na revista Lancet é retirado do ar por autores. Estadão, Ciência, 04 jun. 2020. Disponível em: https://ciencia.estadao.com.br/noticias/geral,estudo-sobre-cloroquina-na-revistalancet-e-retirado-do-ar-por-autores,70003324850. Acesso em: 2020.

GOSTIN, Lawrence O. Global polio eradication: espionage, disinformation, and the politics of vaccination. The Milbank Quarterly, v. 92, n. 3, p. 413, 2014.

GRABNER-KRÄUTER, Sonja; BITTER, Sofie. Trust in online social networks: a multifaceted perspective. In: FORUM for social economics. Routledge, 2015. p. 48-68.

GRENZ, Stanley. Pós-modernismo: um guia para entender a filosofia do nosso tempo. São Paulo: Vida Nova, 1997. 
HAJE, Lara. Projeto do Senado de combate a notícias falsas chega à Câmara. Agência Câmara de Notícias, 03 de julho de 2020. Disponível em:

https://www.camara.leg.br/noticias/673694-projeto-do-senado-de-combate-anoticias-falsas-chega-a-camara/. Acesso em: 2020.

HAMELEERS, Michael; VAN DER MEER, Toni GLA. Misinformation and polarization in a high-choice media environment: How effective are political fact-checkers?.

Communication Research, v. 47, n. 2, p. 227-250, 2020.

HONNETH, A. Luta por reconhecimento: a gramática moral dos conflitos sociais. São Paulo: Ed. 34, 2009.

ITHISUPHALAP, Jaruda; RICH, Patrick R.; ZARAGOZA, Maria S. Does evaluating belief prior to its retraction influence the efficacy of later corrections?. Memory, v. 28, n. 5, p. 617-631, 2020

JAMIESON, Kathleen Hall. Cyberwar: how russian hackers and trolls helped elect a president. New York: Oxford University Press, 2018.

JORNAL NACIONAL (JN), G1. TSE aprova punição com prisão ou multa para quem espalhar fake News. G1, 19 dez. 2019. Disponível em: https://g1.globo.com/jornalnacional/noticia/2019/12/19/tse-aprova-punicao-com-prisao-ou-multa-para-quemespalhar-fake-news.ghtml Último acesso em: 13 de dez. 2020.

KAHAN, Dan M. et al. The polarizing impact of science literacy and numeracy on perceived climate change risks. Nature Climate Change, v. 2, n. 10, p. 732-735, 2012.

KARLOVA, Natasha; FISHER, Karen. A social diffusion model of misinformation and disinformation for understanding human information behavior. Information Research, v. 18, n. 1. 2013.

KNOBEL, Marcelo; ORSI, Carlos. Alerta máximo contra as pseudociências. Folha de São Paulo, 16 jan. 2019. Disponível em:

https://www1.folha.uol.com.br/opiniao/2019/01/alerta-maximo-contra-aspseudociencias.shtml. Acesso em: 2020.

LAKATOS, Imre. Falsification and the Methodology of Research program. In: LAKATOS, I; MUSGRAVE, A. (eds.) Criticism and the growth of knowledge. Cambridge: Cambridge University Press, 1970.

LEAL, Paulo Cesar. A guerra híbrida. Doutrina Militar Terrestre em Revista, v. 4, n. 9, p. 6-17, 2016.

LELO, Thales Vilela. A influência do partidarismo na recepção de fake news e factchecking em contexto de polarização política. Observatorio (OBS*), v. 14, n. 3, 2020.

LIM, Chloe. Checking how fact-checkers check. Research \& Politics, v. 5, n. 3, 2018.

LIMA, Roberto Kant de. Complementaridade e inquisitorialidade, oposição e acusatorialidade: a tradição judiciária da punição de conflitos e a tradição processual da resolução de conflitos, no Brasil. Série Estudos, n. 91, p. 67-85, 1995. 
LIMA, Roberto Kant de; MOUZINHO, Glaucia Maria Pontes. Inquisitorialidade, igualdade jurídica e direitos civis no Brasil: afinal, direitos humanos para quem?. In: A ANTROPOLOGIA e a esfera pública no Brasil. Rio de Janeiro: Coedição Editora Epapers / ABA publicações, 2018. p. 237-272.

LIVINGSTONE, Sônia. Media Literacy and the challenge of new information and communication Technologies. London: LSE Research Online, 2004.

LUBCHENCO, Jane. Environmental science in a post-truth world. Frontiers in Ecology and the Environment, v. 15, n. 1, 2017.

LYOTARD, Jean-François. A condição pós-moderna. Rio de Janeiro: J. Olympio, 1998.

MAHNER, Martin. Demarcating science from non-science. In: GENERAL Philosophy of Science. [S.I.]: North-Holland, 2007. p. 515-575.

MARIETTA, Morgan; BARKER, David C.; BOWSER, Todd. Fact-checking polarized politics: Does the fact-check industry provide consistent guidance on disputed realities?. In: THE FORUM. 2015. p. 577-596.

MEDE, Niels G.; SCHÄFER, Mike S. Science-related populism: Conceptualizing populist demands toward science. Public Understanding of Science, 2020.

MILLER, Seumas. Freedom of Political Communication, Propaganda and the Role of Epistemic Institutions in Cyberspace. In: THE ETHICS of Cybersecurity. 2020. p. 227243.

MOISÉS, José Álvaro. A desconfiança nas instituições democráticas. Opinião Pública, v. 11, n. 1, p. 33-63, 2005.

MOURA, Athos. Deputados pedem que Maia desconvide Felipe Neto para debate na Câmara. O Globo, Blogs, 05 ago. 2020. Disponível em:

https://blogs.oglobo.globo.com/lauro-jardim/post/deputados-pedem-que-maiadesconvide-felipe-neto-para-debate-na-camara.html. Acesso em: 2020.

NOVAES, Allan Macedo. A crise da ciência: pós-modernidade e a prática do jornalismo científico em Superinteressante. Inovcom, v. 1, n. 1, p. 02-11, 2006.

OLIVEIRA, Thaiane. Desinformação científica em tempos de crise epistêmica: circulação de teorias da conspiração nas plataformas de mídias sociais. Fronteiras, v. 22, n. 1, 2020.

OLIVEIRA, Thaiane; QUINAN, Rodrigo; TOTH, Janderson Pereira. Antivacina, fosfoetanolamina e Mineral Miracle Solution (MMS): mapeamento de fake sciences ligadas à saúde no Facebook. Revista Eletrônica de Comunicação, Informação e Inovação em Saúde, v. 14, n. 1, 2020.

ORGANIZAÇÃO MUNDIAL DE SAÚDE - OMS. Benin goes on digital offensive against COVID-19. OMS, 09 abr. 2020. Disponível em: https://www.who.int/newsroom/feature-stories/detail/benin-goes-on-digital-offensive-against-covid-19. Acesso em: 2020. 
PENNYCOOK, Gordon et al. Understanding and reducing the spread of misinformation online. [S.I.: s.n.], 2019.

PICCOLLI, Larlecianne; MACHADO, Lauren; MONTEIRO, Valeska Ferrazza. A guerra híbrida e o papel da Rússia no conflito sírio. Revista Brasileira de Estudos de Defesa, v. 3, n. 1, 2016.

POPPER, Karl. Conjectures and refutations: the growth of scientific knowledge. Nova York: Basic Books, 1962.

RIETJENS, Sebastiaan. Unraveling disinformation: the case of Malaysia Airlines Flight MH17. The International Journal of Intelligence, Security, and Public Affairs, v. 21, n. 3, p. 195-218, 2019.

RODRIGUES, Theófilo Machado; BONONE, Luana; MIELLI, Renata. Desinformação e crise da democracia no Brasil: é possível regular fake news?. Confluências| Revista Interdisciplinar de Sociologia e Direito, v. 22, n. 3, p. 30-52.

RUTSCHMAN, Ana. The reemergence of vaccine nationalism. Georgetown Journal of International Affairs, Forthcoming, 2020.

SAMPAIO, Paulo. Para médica Nise Yamaguchi, comunidade científica conspira contra a vida. UOL, Coluna, 19 jul. 2020. Disponível em:

https://noticias.uol.com.br/colunas/paulo-sampaio/2020/07/19/para-medica-niseyamaguchi-comunidade-cientifica-conspira-contra-a-vida.htm

SHEN, Lijiang; ZHOU, Yanmengqian. Epistemic egocentrism and processing of vaccine misinformation (vis-à-vis scientific evidence): the case of vaccine-autism link. Health Communication, p. 1-12, 2020.

SHETH, Bhavisha P.; THAKER, Vrinda S. Scientific retraction: a synonym for pseudoscience?. Acta Bioethica, v. 20, n. 1, p. 93-97, 2014.

SHIN, Jieun et al. The diffusion of misinformation on social media: Temporal pattern, message, and source. Computers in Human Behavior, v. 83, p. 278-287, 2018.

SIITONEN, A. Demarcation of Science from the Point of View of Problems and Problem-Stating in Philosophy of Science History of Science. Philosophia Naturalis Meisenheim, v. 21, n. 2-4, p. 339-353, 1984

STEFFENS, Maryke S. et al. How organisations promoting vaccination respond to misinformation on social media: a qualitative investigation. BMC Public Health, v. 19, n. 1, p. 1-12, 2019.

TALWAR, Shalini et al. Why do people share fake news?: associations between the dark side of social media use and fake news sharing behavior. Journal of Retailing and Consumer Services, v. 51, p. 72-82, 2019.

THALER, Andrew David; SHIFFMAN, David. Fish tales: combating fake science in popular media. Ocean \& Coastal Management, v. 115, p. 88-91, 2015.

TÖRNBERG, Petter. Echo chambers and viral misinformation: modeling fake news as complex contagion. PLoS one, v. 13, n. 9, p. e0203958, 2018. 
TUFTE, Thomas. Estudos de mídia na América Latina. Comunicação \& Sociedade, n. 25, 1996.

UNESCO. Media and information literacy: reinforcing human rights, countering, radicalization and extremism. 2016.

VAN DE WALLE, Steven; SIX, Frédérique. Trust and distrust as distinct concepts: why studying distrust in institutions is important. Journal of Comparative Policy Analysis: Research and Practice, v. 16, n. 2, p. 158-174, 2014.

VAN PUYVELDE, Damien. Hybrid war: does it even exist?. NATO Review, 2015.

VAN ZOONEN, Liesbet. I-pistemology: changing truth claims in popular and political culture. European Journal of Communication, v. 27, n. 1, p. 56-67, 2012.

WALLACE, Rob et al. COVID-19 and circuits of capital. Monthly Review, v. 72, n. 01, 2020.

WALTER, Nathan et al. Fact-checking: A meta-analysis of what works and for whom. Political Communication, v. 37, n. 3, p. 350-375, 2020.

WALTER, Nathan; MURPHY, Sheila T. How to unring the bell: A meta-analytic approach to correction of misinformation. Communication Monographs, v. 85, n. 3, p. 423-441, 2018.

WARDLE, Claire; DERAKSHAN, H. Information disorder: toward an interdisciplinary framework for research and policy making. RM. Retrieved from, 2017.

WEINGART, Peter; GUENTHER, Lars. Science communication and the issue of trust. Journal of Science communication, v. 15, n. 5, p. C01, 2016.

$\mathrm{XU}$, Yi et al. Is it smart to read on your phone?: the impact of reading format and culture on the continued influence of misinformation. Memory \& Cognition, 2020. 